\title{
Note on Orthography and Sherpa Names
}

It is anomalous that no accepted convention exists for writing the language of a group as famous, well studied, and thoroughly documented as the Sherpas. Because Sherpa, unlike closely related Tibetan, is not a written language, there are no indigenous texts that could be used to generate a systematic transliteration into roman letters. I have therefore had to settle for the same method others have used, namely, to write Sherpa words as close to the way they sound as possible and to check these phonetic renderings with native speakers of Sherpa who also speak, read, and write Nepali and English.

But there is no clear-cut solution to the linguistic conundrums posed by this orthographic task. For instance, I use gompa, glossed as "temple, monastery," because this transliteration is closer to the original Tibetan (the conventional, letter-for-letter scholarly version would be dgon-pa) than gomba, which others have used. Neither spelling, however, approximates the spoken Sherpa equivalent, "gonda." I use the Tibetan word only because of its more general familiarity to those interested in Tibetan Buddhism. Similarly, I refer to Rongbuk (rather than the more phonetically faithful Rumbu) Monastery.

Place names pose their own difficulties. The village I spell Khunde others have written Kunde, but neither spelling reflects the pronunciation of the word when it is written in Tibetan script-Khumte, meaning the upper $(t e)$ Khum, as opposed to Khumjung, the Khum located on a flat place at a lower elevation (jung). As for Khumjung, Ortner (1989) reports that Hari Ram, an Indian explorer who made the first recorded 
visit to Khumbu by a foreigner, in 1885 , called it Khumbu Dzong (Khurnbu fort). Although this sort of name is common in Tibetanspeaking areas, it seems etymologically odd here since there is no structure in Khumjung remotely resembling a fort. Whether Hari Ram's rendering, or my own, is a folk etymology, I do not know.

In any case, Sherpas believe that "Khumte" must have been the original correct pronunciation, since it has a recognizable meaning, rather than "Khunde," which they regard as a corruption of the pristine term. But "Khunde" is invariably the spoken form and hence the spelling I use here.

All Sherpas have dual names, one element of which is often the day of the week on which they are born:

Monday Dawa (Da)
Tuesday Mingma
Wednesday Lhakpa
Thursday Phurba (Prua)
Friday Pasang
Saturday Pemba
Sunday Nima

Such a name may be followed by a second name, such as Tsering, meaning "long life," giving combinations like Mingma Tsering; or it may be preceded by Ang, meaning "young," resulting in names like Ang Nima. Because the number of such compounds is small, several individuals often share the same name. In this book alone, for example, which contains relatively few Sherpa names, there are four Ang Tserings and two Ang Ritas.

Foreigners tend to keep individuals with duplicate names straight by specifying locality: for example, the Khumjung Ang Rita versus the Khunde Ang Rita. Sherpas distinguish them by specifying locality or clan or some other relationship: for example, the Ang Rita who is the son of Mingma Tsering versus the Ang Rita who is the son of Kappa Kalden.

Sherpas do not normally have a "last name." When they live elsewhere in Nepal or travel to foreign countries, the word Sherpa begins functioning as a last name, as on passports or on school registration forms. But this is a modern affectation without foundation in SoluKhumbu, where such a system would give everyone the same last name. 


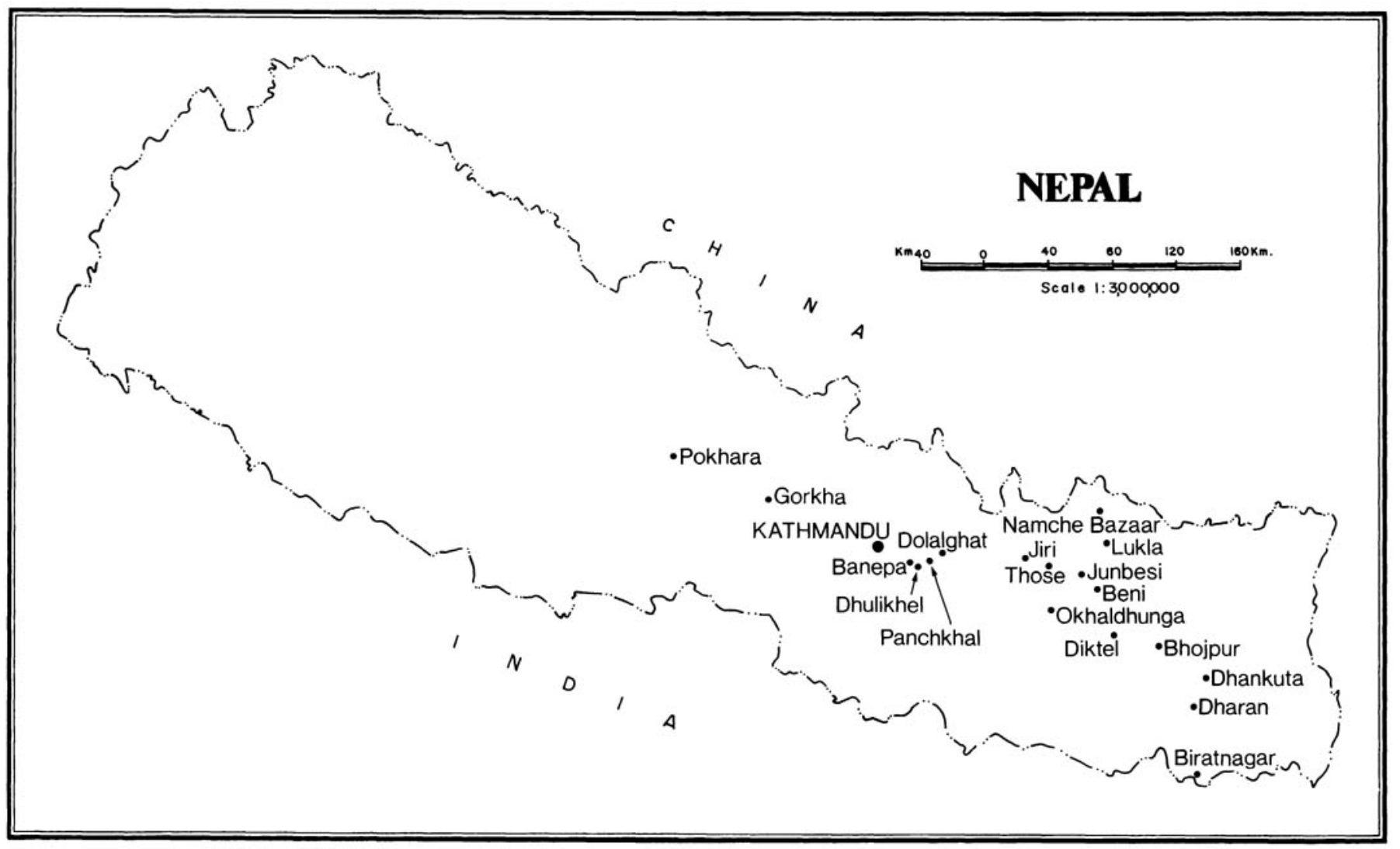




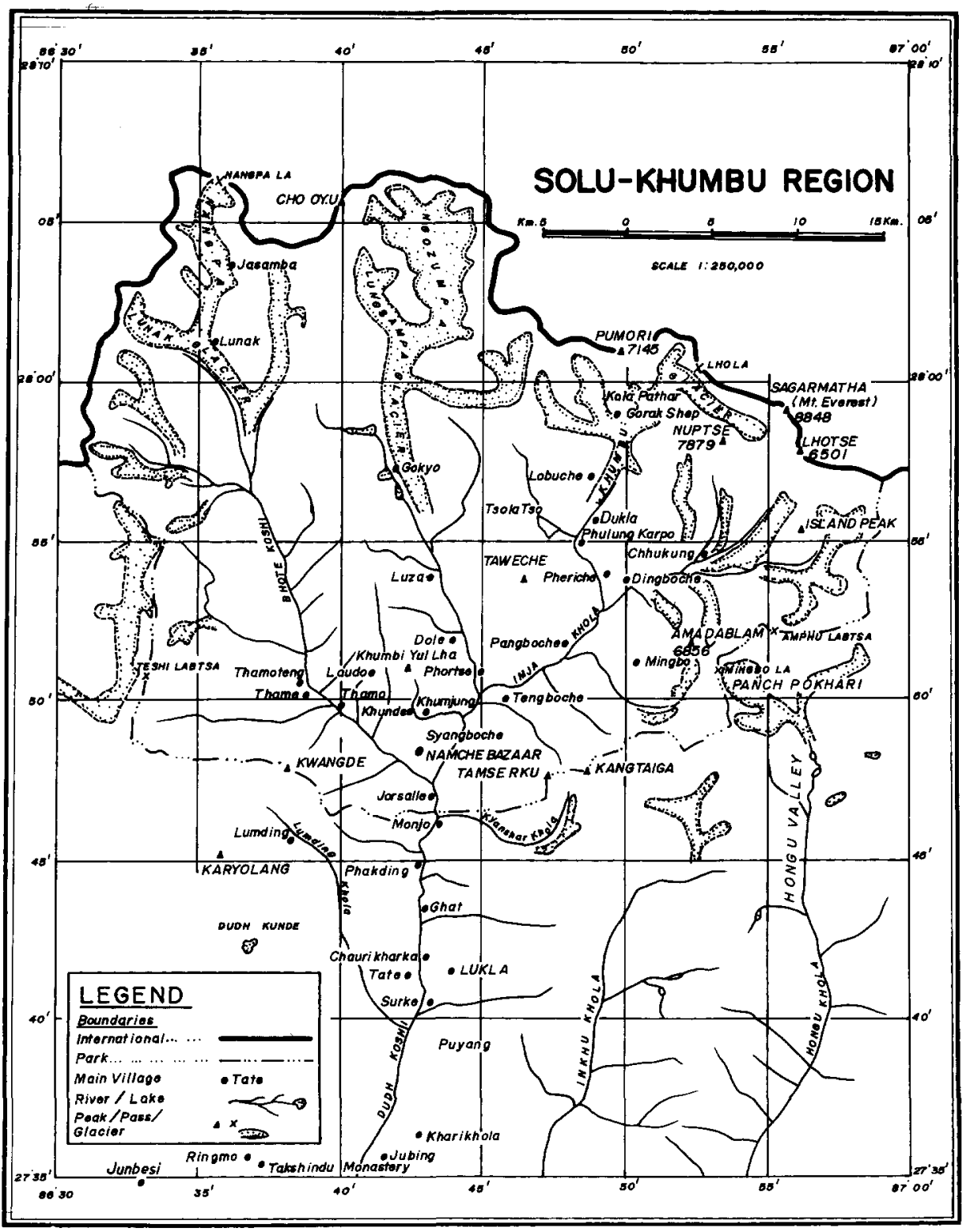




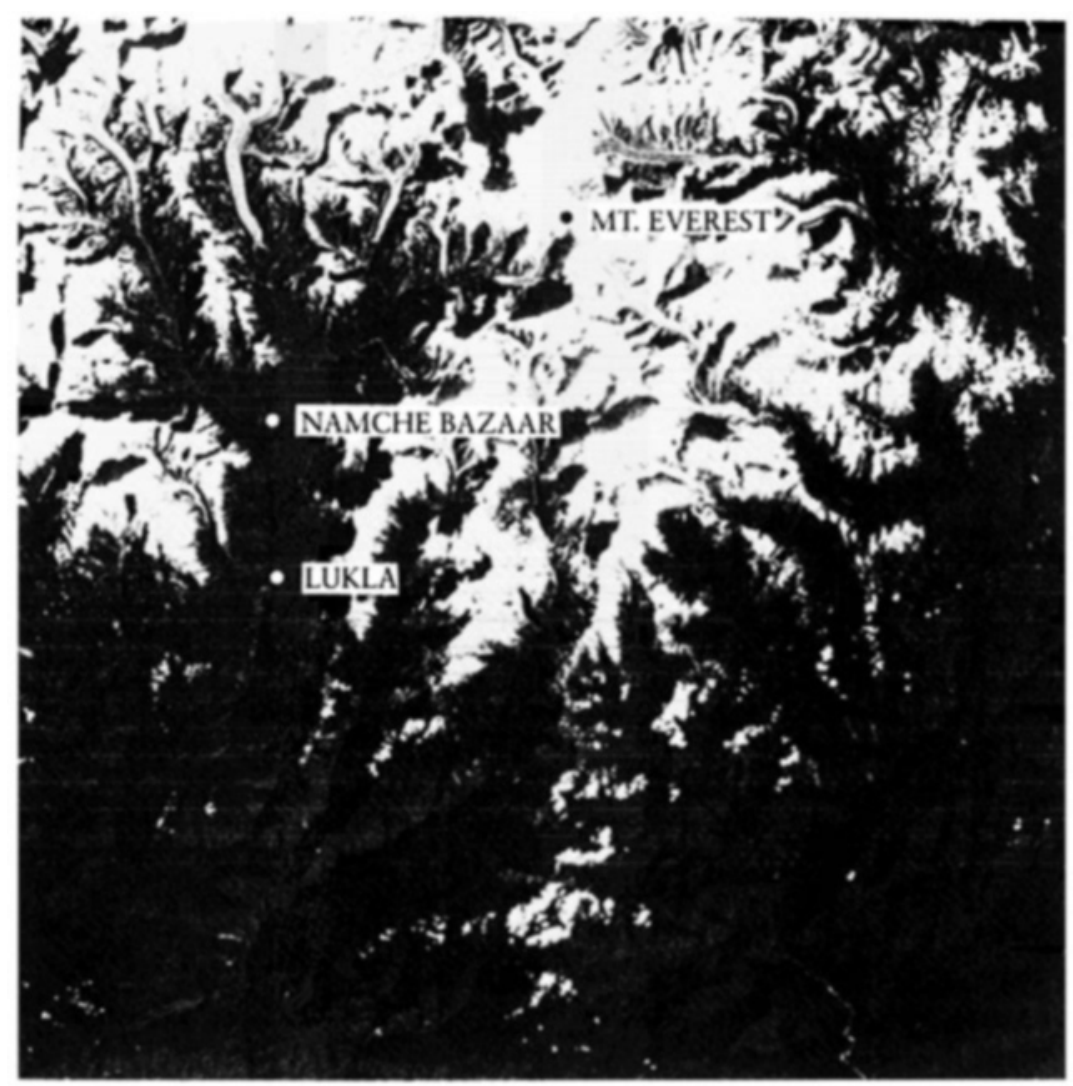

Satellite view of Solu-Khumbu. (C) 1990 DRL West Germany. 
This page intentionally left blank 